been less productive of good ideas and that on many occasions they can rely on the good sense of working scientists to anticipate trouble.

There will be few complaints in the United States if the defence authorities now seek to build on this goodwill. It would be entirely proper that they should remind people in laboratories that even seemingly academic developments may have defence implications. Equally, it would be proper that university administrations should take a continuing interest in the problem. It would, however, be a mistake for the military authorities to set up central machinery for supervising academic papers before publication. Such a system could prevent the publication of sensitive material only by holding up a great deal of innocuous material. Even then, it would make mistakes. It would be far preferable that responsibility for deciding how the publication of potentially sensitive material should be arranged should rest with researchers and their universities. The proposed arrangements for supervising research in cryptography, designed to shut the stable door after the bolted horse, should be abandoned.

The general run of military research proper is more easily handled. Since 1940, the Defense Department has learned to rely on American universities for a substantial part of its research and development. Academics are well used to this kind of collaboration, and are apparently able without too much difficulty to marry their obligations to liberal teaching with their obligations of confidentiality to the Pentagon. Whether the topic is formally registered as secret, or "classified", seems not to matter. A more important consideration is that there are limits to the degree to which the university system can be laden with responsibilities for defence research without being compromised. The irony is that, in the present economic climate, the universities are more willing collaborators and that the Pentagon seems glad of the welcome it now seems to enjoy from the universities.

The issue of commercially important research is novel and fuzzier. During the past decade, government agencies have been increasingly anxious that publicly supported research should have some practical relevance while, more cautiously, corporations have begun to recognize the potential of the academic research enterprise. What seems not to have been appreciated is that many of those who help to carry through these unclassified programmes are nationals of countries other than the United States.

But what is so strange about that? For even the most "relevant" of externally supported research programmes are not - and should not be - programmes of development. Most of them are projects intended to gather basic information in some obvious field. The fear that foreign visitors may carry off unique information in fields such as the molecular biology of genetic engineering or the development of techniques for making Very Large Integrated circuits is predicated on the assumption that nobody else knows about these important industrial goals. That conceit is almost always an illusion. It should not be allowed to compromise the civility and freedom of academic research. In any case, the agencies and the corporations have the remedy in their own hands. They decide what research contracts should be let.

\section{Why arms control?}

\section{Will arms control fall foul of too literal an interpretation of Kissinger détente?}

This has been a bad week for arms control. Mr Alexander Haig's long-arranged meeting with $\mathrm{Mr}$ Andrei Gromyko in Geneva was being advertised in advance, in Washington at least, as a discussion exclusively about recent events in Poland. The promised resumption of bilateral negotiations on strategic arms are apparently to be postponed indefinitely. At the same time, there have been mutterings in Washington that the talks now under way in Geneva on the control of weapons in Central Europe may be reduced to one session a week unless there is some sign of let-up in martial law from Warsaw. Both developments are consistent with the case argued forcefully last week by Dr Henry
Kissinger, previously United States Secretary of State and the architect both of the concept of detente and of several arms control agreements between the Soviet Union and the United States. In two pungent articles, Dr Kissinger restated his familiar argument that peace is indivisible, and that a succession of agreements on arms control is in itself insufficient, even insubstantial. The present Administration has obviously been angered by much of what he said. Its responses this week suggest that it is nevertheless prepared to listen.

Can this be wise? The Kissinger doctrine of "linkage" is politically and tactically impeccable. In making an accommodation with an adversary, and on the assumption that neither side will abandon what it considers to be its essential interests overnight, it is prudent to seek agreements which provide each side with incentives to toe the line and deterrents (not necessarily nuclear) against backsliding. The essence of the Kissinger-Nixon theory of detente is that the United States would offer the carrot of high technology and trade, gaining in return the relatively insubstantial benefits of the Helsinki agreements and of détente itself. The corresponding deterrents were ultimately supposed to be what they have been ever since 1946. One essential element in Dr Kissinger's argument, not restated but substantially unchanged, is that it should be possible to withdraw the carrots quickly, making the sticks loom larger. Dr Kissinger last week was scornful of the growing United States dependence on the international trade with the Soviet Union in foodstuffs. His articles appeared before France had followed West Germany in agreeing to buy substantial quantities of natural gas from the Soviet Union. but his arguments do not apply, as seems to be supposed, to the process of negotiating, as distinct from ratifying, agreements on arms control.

That conclusion can be reached without much difficulty. The experience of the past few years has shown that the parties most acutely embarrassed in negotiations are those who feel bound to reject sensible proposals. The United States Administration has turned up at Geneva with an in-built advantage - President Reagan's declaration in November that he (but not necessarily Congress) would settle for the "zero option" - no nuclear missiles (as distinct from aircraft) of any kind in Europe. The general opinion, borne out by such official Soviet statements as there have since been, is that Mr Reagan was offering a clever bargain, as much a stick as a carrot. Does it make sense, having raised such a possibility, to allow the discussion of this proposal to slip into the background noise, like the continuing negotiations in Vienna on the reduction of conventional forces in Europe? For that matter, can it make sense, if the United States seriously believes it has a moral advantage because of Poland, that Mr Haig should so ostentatiously fail to raise with Mr Gromyko the matter of how far the Soviet Union might be prepared to go on a replacement treaty for Salt II?

The underlying difficulty is that, on arms control, while the more important negotiations are bilateral between the United States and the Soviet Union, neither party is as free as it supposes. Paradoxically, the negotiators must constantly have in mind the electorates of countries other than their own. Or they should. The willingness of the government of France to contract for a decade's supply of natural gas from the Soviet Union should be a reminder that France is a European state. The nervousness of the Bonn government about the future of Central Europe is also a measure of the more general concern that alternative governments would pose more complicated problems. And who supposes that all members of the Soviet government have slept soundly at nights during the past momentous eighteen months? Mr Haig should talk, not sulk.

The moral is, or should be, simple. Talking about arms control is better than sulking. Talking about arms control to a potential partner at a moral disadvantage may be especially productive. Not to talk at all, or to talk only one day a week, is silly. And is there not always a chance that the process will itself be worthwhile? In short, the United States should feel free to speak up at Geneva and elsewhere without fear of selling itself short or of offending Dr Kissinger. 